Обоснование. Ожирение у детей относится к числу предотвратимых заболеваний, а результаты научных исследований демонстрируют активный поиск причин и путей решения данной проблемы. Наряду с основными причинами в настоящее время активно изучается роль естественных гормонов в патогенезе ожирения.

Цель. Определение взаимосвязи уровня сывороточного несфатина с нарушениями липидного обмена у детей школьного возраста с избыточной массой тела и ожирением.

Методы. Исследование проведено с участием детей с избыточной массой тела и ожирением («случай») и нормальной массой тела («контроль») в возрасте от 9 до 15 лет. У всех детей определяли концентрации в крови холестерина и его фракций, апоА-1, апоВ. Исследование уровня сывороточного несфатина-1 в сыворотке определяли методом конкурентного иммуноферментного анализа (Ray Bio Human Nesfatin Enzyme Immunoassay Kit). Период исследования - с октября 2018 по февраль 2019 г.

Результаты. Группы пациентов с избыточной массой и ожирением $(\mathrm{n}=53)$ и нормальной массой тела ( $\mathrm{n=31)}$ были сопоставимы по полу и возрасту. У детей с ожирением выявлено достоверное снижение уровня несфатина-1, особенно выраженное при наличии дислипидемии по сравнению с группой с нормальной массой тела. Уровень несфатина-1 отрицательно коррелирует с ИМТ, содержанием жира в организме (\%ЖМ).

Заключение. Полученные результаты дают основание предполагать, что, наряду с известной ключевой ролью несфатина в регуляции пищевого поведения и аппетита, он также влияет на антропометрические показатели, прежде всего связанные с накоплением избыточной жировой массы. На основании полученных данных несфатин-1 следует рассматривать как потенциальный маркер развития ожирения у детей.

КЛЮЧЕВЫЕ СЛОВА: несратин-1; дети; холестерин; избыточная масса; ожирение.

\title{
SERUM NESFATIN IN OVERWEIGHT AND OBESE CHILDREN
}

(c) Vladimir V. Bazarnyi, Elena V. Anufrieva*, Arina Yu. Maksimova, Larisa G. Polushina, Olga P. Kovtun

Ural State Medical University, Ekaterinburg, Russia

BACKGROUND: Obesity is one of the most common children diseases. In present time it is being actively studied the natural hormones role in the pathogenesis of obesity.

AIMS: To determine the relationship between serum nesfatin level with impaired lipid metabolism in school age children with overweight and obesity.

MATERIALS AND METHODS: The study included children with overweight and obesity («case») and healthy children with normal body mass («control») aged 9 to 15 years. All children were determined by concentration in cholesterol blood and its factions, apoA-1, apoB. Enzyme-linked immunosorbent assay (Bio Human Nesfatin Enzyme Immunoassay Kit).

RESULTS: Groups of patients with overweight and obesity $(n=53)$ and healthy children $(n=31)$ were comparable by age and sex. In obese children, a significant decrease in the level of nesfatin-1 was revealed compared with the group with normal body weight. In cases of children obesity there is a marked decrease in the concentration of nesfatin-1 in serum, especially expressed in the dyslipidemia presence. The nesfatin-1 level are negatively correlated to BMI and body fat content.

CONCLUSIONS: The obtained data suggest that along with the known key role of nesfatin in the regulation of eating behavior and appetite, it also affects anthropometric indicators, primarily associated with the accumulation of excess fat mass. Based on the data obtained, nesfatin-1 should be considered as a possible marker for the development of obesity in children.

KEYWORDS: nesfatin-1; child; cholesterol; overweight; obesity.

\section{ОБОСНОВАНИЕ}

Ожирение у детей является одной из самых серьезных медико-социальных проблем XXI в. Показатели детского и подросткового ожирения во всем мире увеличились с менее чем 1\% в 1975 г. до 6\% среди девочек и почти 8\% среди мальчиков в 2016 г. [1]. Ожирение и предшествующее его развитию накопление избыточной массы тела у ребенка ведут к развитию различных морфофункциональных нарушений развивающегося организма. Проблема ранней диагностики избыточной массы тела, формирования групп риска развития ожирения является актуальной. Основной диагностический критерий избыточной массы в практике врачей- 
педиатров - индекс массы тела (ИМТ) [2, 3]. Использование единых подходов к оценке физического развития у детей и подростков врачами-педиатрами и детскими эндокринологами способствует своевременному выявлению отклонений $[4,5]$. Однако до настоящего времени в повседневной практике не все врачи-педиатры проводят оценку ИМТ и самостоятельно выставляют диагноз «ожирение». Это приводит к несвоевременному направлению детей на консультацию к эндокринологу и прогрессированию избыточной массы тела $[5,6]$. Между тем понимание причин формирования ожирения у детей и подростков требует как интерпретации взаимосвязи между уже известными факторами, так и поиска новых механизмов патогенеза. Они не ограничиваются влиянием поведенческих детерминант (неправильное питание, гиподинамия), генетическими и другими факторами [7]. Определенную роль в нарушении массы тела у детей играет нарушение регуляторных механизмов [8].

Ключевым регулятором многих функций, в том числе - метаболизма и пищевого поведения, является гипоталамус, продуцирующий комплекс регуляторных пептидов $[9,10]$. В сложной иерархии регуляторов массы тела в последние годы привлекает внимание несфатин-1 - полипептид, открытый только в 2006 г., поэтому активно изучаемый исследователями. Он обладает плейотропной активностью, в частности, показано его участие в регуляции метаболизма липидов и глюкозы, функций желудочно-кишечного тракта, периферической и центральной нервной системы, отмечена связь несфатина с сердечно-сосудистыми заболеваниями [11-14]. Однако большинство проведенных в мире исследований рассматривают «взрослую популяцию» с ожирением или с патологией, которая не встречается у детей и подростков (гестационный диабет и др.). Учитывая вышеизложенное, определение роли несфатина-1 в развитии ожирения у детей следует считать актуальным вопросом.

\section{ЦЕЛЬ}

Определение взаимосвязи уровня сывороточного несфатина-1 с нарушениями липидного обмена у детей школьного возраста с избыточной массой тела и ожирением.

\section{МЕТОДЫ}

\section{Дизайн исследования}

Проведено обсервационно-аналитическое сравнительное исследование по типу «случай-контроль».

\section{Критерии соответствия}

Критерии включения в основную группу «случай»: учащиеся общеобразовательных школ в возрасте от 9 до 15 лет включительно, с диагнозом избыточной массы тела или ожирения.

Критерии исключения: сопутствующая эндокринная патология, сахарный диабет, наличие инсулинорезистентности, гормональная терапия.

Критерии включения в группу «контроль»: возраст от 9 до 15 лет включительно, дети на момент обследования практически здоровые (по заключению врачапедиатра центра здоровья).

\section{Условия проведения}

Исследование проведено на базе муниципального автономного учреждения города Екатеринбурга «Городская поликлиника №13», центр здоровья длядетей. Лабораторные исследования выполнены в центральной научно-исследовательской лаборатории ФГБОУ ВО УГМУ Минздрава России, отделе общей патологии.

\section{Продолжительность исследования}

Исследование проведено в период с октября 2018 по февраль 2019 гг. Набор детей в контрольную группу осуществлялся в этот же период после прохождения ими обследования в центре здоровья и заключения врача-педиатра.

\section{Описание медицинского вмешательства}

Проводилось измерение соматометрических показателей - роста, массы тела по стандартной методике. Дополнительно определяли компонентный состав тела путем биоимпедансометрии. Измеряли абсолютные значения жировой массы (ЖМ), активной клеточной массы (АКМ), основного обмена веществ и общей жидкости в организме. Оценивали процентное содержание жира в организме (\%ЖМ) и процентную долю активной клеточной массы в безжировой массе (\%АКМ). Забор крови проводился в утренние часы. Биохимический анализ крови включал определение следующих параметров: общего холестерина (OX), холестерина липопротеидов высокой плотности (ХС-ЛПВП) и холестерина липопротеидов низкой плотности (XС-ЛПНВ), аполипопротеинов A1 и В (апоА-1, апоB), глюкозы, несфатина-1.

Сбор жалоб и анамнестических данных осуществлялся непосредственно от пациентов и их родителей. В анамнезе детализировались жалобы, возраст появления избыточной массы тела, повышенный аппетит, наличие эпизодов повышения артериального давления.

\section{Основной исход исследования}

Уровень несфатина-1 в сыворотке крови в группе детей с ожирением в сравнении со здоровыми детьми. Установление взаимосвязи концентрации несфатина-1 с антропометрическими показателями и параметрами липидного обмена.

\section{Дополнительные исходы исследования}

Процентное содержание жировой и активной клеточной массы тела, значения показателей липидного обмена у детей школьного возраста в зависимости от статуса питания.

\section{Анализ в подгруппах}

Дети основной группы были разделены на две подгруппы с избыточной массой тела и ожирением.

Также из основной группы детей была выделена подгруппа детей с низким уровнем концентрации несфатина-1.

\section{Методы регистрации исходов}

Концентрацию несфатина-1 в сыворотке определяли методом конкурентного иммуноферментного анализа (Ray Bio Human Nesfatin Enzyme Immunoassay Kit). Содержание несфатина-1 в сыворотке крови 1,0 нг/мл и менее 
рассматривали как низкий уровень концентрации. Определение общего холестерина проводили ферментативным методом (CHOD-PAP), ХС-ЛПВП и ХС_ЛПНП- прямым методом без осаждения на анализаторе Sapphire TM 400 (Hirose Electronic System) в автоматическом режиме. Определение апоА-1 и апоВ выполняли иммунотурбидиметрическим методом, учет реакции осуществляли с помощью спектрофотометра Multiskan GO (Thermo Scientific). Использованы тест-системы DiaSys (Германия).

На основании антропометрических показателей рассчитывали индекс массы тела (ИМТ), который определяется как отношение массы тела ребенка в килограммах к росту в метрах, возведенному в квадрат [2]. Физическое развитие оценивали на основании норм роста с помощью программного средства ВО3 AnthroPlus (5-19 лет) для персональных компьютеров по общепринятой методике. Диагноз «ожирение» устанавливали в соответствии с критерием ВО3 $[2,15]$ при значении ИМТ, превышающем средний показатель для данного возраста и пола более чем на два стандартных отклонения (SDS), «избыточная масса тела» - соответственно при значении ИМТ от+1SDS до +2SDS. \%ЖМ и \%АКМ в организме измеряли на анализаторе импедансного состава тела - комплекс КМ-АР-01, комплектация «ДИАМАНТ-АИСТ» (v.11.05, прибор №178079).

\section{Этическая экспертиза}

Исследование одобрено локальным этическим комитетом Уральского государственного медицинского университета (протокол №8 от 19.10.2018). Все участники исследования или их законные представители подписывали информированное согласие на участие в исследовании и на обработку персональных данных.

\section{Статистический анализ}

Принципы расчета размера выборки. Размер выборки предварительно не рассчитывался.

Методы статистического анализа данных. Полученные данные обрабатывали с помощью пакета статистических программ Statistica версии 10.0 for Windows (StatSoft Inc., США). При нормальном распределении (холестерин и его фракции) данные представлены как среднее значение и стандартное отклонение $(\mathrm{M} \pm \delta)$. При описании данных, распределение, которых отличалось от нормального (аполипопротеины и несфатин-1), рассчитывали медиану (Ме) и доверительный интервал (ДИ); рассчитывали коэффициент корреляции Спирмена (r). Достоверность различий значений признаков между группами определялась с использованием F-критерия Фишера, различия считались статистически значимыми при $\mathrm{p}<0,05$.

\section{РЕЗУЛЬТАТЬ}

Объекты (участники) исследования

В исследование включены 53 ребенка с избыточной массой тела и ожирением, средний возраст $11,9(10 ; 14)$ года, мальчики (64\%), сформировавших основную группу. В контрольную группу включены 31 практически здоровый ребенок с нормальной массой тела в возрасте 11 (10; 13) лет, мальчики (58\%). Статистически значимых различий по возрасту и полу не обнаружено $(p=0,319)$.

Из основной группы детей дополнительно была выделена подгруппа из 26 человек (49\%) с низким уровнем концентрации несфатина-1 в сыворотке крови -1,0 нг/мл и менее.

Согласно проведенному статистическому анализу, в основной группе избыточная масса тела зарегистрирована в 39,6\%, ожирение - в 60,4\% случаев. Значения SDS ИМТ в группе с ожирением - 2,81 (2,2; 3,1), с избыточной массой тела - 1,64 (1,4; 1,8), в группе контроля $0,3(-0,3 ; 0,7)$. Группы статистически значимо различаются (критерий сравнения долей $\mathrm{p}<0,001)$.

Длительность заболевания, наличия избыточной массы тела от 1 до 3 лет была у 15 (28\%) детей основной группы, от 3 до 5 лет - у 28 (53\%), более 5 лет - у 10 (19\%). Жалобы на увеличение массы тела предъявляли 22 (41\%) ребенка, повышенный аппетит (большие объемы порций, частые приемы пищи) - 32 (60\%) пациента, периодическое повышение АД у ребенка отмечали 8 (15\%) родителей.

\section{Основные результаты исследования}

Уровень несфатина-1 в сыворотке крови детей с ожирением был статистически значимо ниже, чем в контрольной группе: медиана значения в основной группе - 1,0 нг/мл (доверительный интервал (ДИ) 0,1; 12,7), в контроле 11,0 нг/мл (ДИ 6,7; 21,0), р<0,01. В группе детей с ожирением при нормальных показателях липидного обмена концентрация сывороточного несфатина-1 была снижена до 1,96 нг/мл (ДИ 0,8; 12,7), тогда как при ожирении в сочетании с дислипидемией - 0,41 нг/мл (ДИ 0,1;1,3), р<0,001.

На основании оценки взаимосвязи несфатина-1 с особенностями липидного обмена в подгруппе детей с уровнем концентрации полипептида в сыворотке крови 1,0 нг/мл и менее установлено, что снижение данного показателя сопряжено с «неблагоприятными» изменениями липидного профиля - снижением ХС-ЛПВП и повышением ХС-ЛПНП, общего холестерина (табл. 1). Была выявлена положительная взаимосвязь между уровнем несфатина в сыворотке и \%АКМ $(r=0,45)$ и отрицательная корреляция с \%ЖМ $(r=-0,39)$, ИМТ $(r=-0,42) p<0,01$. Также

Таблица 1. Взаимосвязь несфатина-1 и показателей липидного обмена у детей с ожирением

\begin{tabular}{|c|c|c|c|c|c|c|c|}
\hline Показатель & & $\begin{array}{l}\text { ИMT, } \\
\mathrm{Kr} / \mathrm{M}^{2}\end{array}$ & $\begin{array}{l}\text { ХС ЛПВП, } \\
\text { ммоль/л }\end{array}$ & $\begin{array}{c}\text { ХС лПНП, } \\
\text { ммоль/л }\end{array}$ & $\begin{array}{c}\text { anoA-1, } \\
\text { г/л }\end{array}$ & $\begin{array}{c}\text { anoB, } \\
\text { г/л }\end{array}$ & $\begin{array}{l}\text { глюкоза, } \\
\text { ммоль/л }\end{array}$ \\
\hline \multirow{2}{*}{ Несфатин-1 } & $r$ & $-0,42$ & $-0,73$ & 0,42 & $-0,79$ & 0,51 & 0,41 \\
\hline & $\mathrm{p}$ & $<0,001$ & 0,002 & 0,013 & 0,011 & 0,014 & 0,034 \\
\hline
\end{tabular}

Примечание. ИМТ - индекс массы тела; ХС ЛПВП/ЛПНП - холестерин липопротеидов высокой/низкой плотности; апоА-1 - аполипопротеин А1; апоВ - аполипопротеин B; r - коэффициент корреляции Спирмена; $\mathrm{p}$ - достоверность коэффициента корреляции. 
этот показатель отрицательно коррелирует с повышенным аппетитом $(r=-0,42), p<0,01$.

При оценке уровня несфатина у 4 пациентов из основной группы с жалобами на периодические подъемы АД было установлено повышение уровня несфатина до 25,12 22,5 нг/мл, что существенно выше, чем у пациентов, не отметивших у себя данных жалоб, $p<0,001$.

\section{Дополнительные результаты исследования}

В предварительном исследовании [16] нами было показано отсутствие значимых половозрастных различий в исследуемых группах: школьники с избыточной массой тела имели более высокие показатели массы тела, ИМТ. С возрастом во всех группах установлен рост ИМТ и абсолютных значений компонентов состава тела (жировой, активной клеточной и безжировой массы тела). Вместе с тем у детей с избыточной массой тела установлено статистически значимое увеличение процентного содержания жира в организме: в группе с ожирением - до 33\% $(30 ; 41)$, с избыточной массой тела - до $25 \%(21 ; 28)$ против $18 \%(13 ; 21)$ в группе контроля $(p<0,001)$. Данные изменения регистрировались на фоне снижения доли активной клеточной массы у детей с ожирением - 43\% $(41 ; 45)$ и избыточной массой тела - 48\% (45; 49) против $54 \%(51 ; 56)$ в группе с нормальной массой тела $(p<0,001)$.

Оценка взаимосвязи внутри групп показала наличие прямой сильной корреляции между ИМТ и \%ЖМ ( $\mathrm{r}=0,80$ в основной группе и $r=0,78$ в контрольной, $p<0,001)$ и обратной корреляции между \%АКМ и ИМТ ( $r=-0,49$ и $r=-0,45$ соответственно, $\mathrm{p}<0,001)$. Также установлена обратная взаимосвязь между процентным содержанием ЖМ и AKM ( $r=-0,90$ и $r=-0,77$ соответственно, $p<0,001)$.

Изученные параметры липидного обмена у детей основной группы не отличались от показателей контрольной группы (табл. 2). При этом у 24\% школьников с ожирением концентрация ОХ была повышена до уровня >4,55 ммоль/л. Несмотря на то что в целом в данной группе концентрации OX и XС-ЛПНП находились в пределах референсных значений, отмечена тенденция к увеличению значений показателей в сравнении с таковыми у практически здоровых детей. Вместе с тем уровни ХС-ЛПВП характеризовались снижением по сравнению с контрольной группой, что указывает на развитие дислипидемии (табл. 3).

Нежелательные явления
Нежелательные явления отсутствовали.

\section{ОБСУЖДЕНИЕ}

Резюме основного результата исследования

В исследовании показано, что у детей школьного возраста с ожирением зарегистрированный сывороточный уровень несфатина-1 был значимо ниже, чем у детей

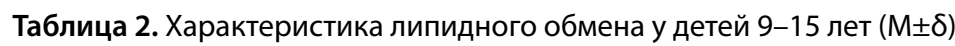

\begin{tabular}{|c|c|c|c|c|}
\hline \multirow[t]{2}{*}{ Показатель } & $\begin{array}{c}\text { Ожирение } \\
n=32\end{array}$ & $\begin{array}{c}\text { Избыточная масса } \\
n=21\end{array}$ & $\begin{array}{c}\text { Нормальная масса } \\
\mathrm{n}=31\end{array}$ & $\mathbf{P}$ \\
\hline & 1 & 2 & 3 & \\
\hline SDS ИMT & $2,81(2,2 ; 3,1)$ & $1,64(1,4 ; 1,8)$ & $0,3(-0,3 ; 0,7)$ & $\begin{array}{l}1: 3<0,001^{*} \\
2: 3<0,001^{*}\end{array}$ \\
\hline$\% Ж M$ & $33(30 ; 41)$ & $25(21 ; 28)$ & $18(12 ; 21)$ & $\begin{array}{l}1: 3<0,001^{*} \\
2: 3<0,001^{*}\end{array}$ \\
\hline Общий холестерин, ммоль/л & $4,4 \pm 0,57$ & $4,2 \pm 0,65$ & $4,03 \pm 0,78$ & $\begin{array}{l}1: 3=0,008^{*} \\
2: 3=0,130\end{array}$ \\
\hline ХС ЛПВП, ммоль/л & $1,1 \pm 0,24$ & $1,3 \pm 0,27$ & $1,4 \pm 0,19$ & $\begin{array}{l}1: 3=0,052 \\
2: 3=0,386\end{array}$ \\
\hline ХС ЛПНП, ммоль/л & $2,7 \pm 0,49$ & $2,4 \pm 0,54$ & $1,9 \pm 0,44$ & $\begin{array}{l}1: 3=0,035^{*} \\
2: 3=0,052\end{array}$ \\
\hline
\end{tabular}

Примечание. М - среднее значение; $\delta$ - стандартное отклонение от среднего; SDS ИМT - оценка стандартного отклонения индекса массы тела; \% ЖМ - доля жировой массы тела; ХС ЛПВП/ЛПнП - холестерин липопротеидов высокой/низкой плотности. *различия статистически значимы при сравнении исследуемых групп.

Таблица 3. Содержание аполипопротеинов и несфатина у детей 9-15 лет (Ме, ДИ)

\begin{tabular}{|c|c|c|c|c|}
\hline \multirow[t]{2}{*}{ Показатель } & $\begin{array}{c}\text { Ожирение } \\
n=32\end{array}$ & $\begin{array}{c}\text { Избыточная масса } \\
n=21\end{array}$ & $\begin{array}{c}\text { Нормальная масса } \\
n=31\end{array}$ & \multirow[t]{2}{*}{$\mathbf{p}$} \\
\hline & 1 & 2 & 3 & \\
\hline Аполипопротеин А1, г/л & $\begin{array}{c}1,7 \\
\text { (ДИ 1,58; 1,9) }\end{array}$ & $\begin{array}{c}1,73 \\
(Д И 1,5 ; 2,2)\end{array}$ & $\begin{array}{c}1,93 \\
\text { (ДИ 1,88; 2,3) }\end{array}$ & $\begin{array}{l}1: 3=0,039^{*} \\
2: 3=0,043^{*}\end{array}$ \\
\hline Аполипопротеин В, г/л & $\begin{array}{c}0,83 \\
\text { (ДИ 0,6; 1,07) }\end{array}$ & $\begin{array}{c}0,69 \\
\text { (Ди 0,55; 0,85) }\end{array}$ & $\begin{array}{c}0,68 \\
\text { (ДИ 0,59; 0,84) }\end{array}$ & $\begin{array}{l}1: 3=0,021^{*} \\
2: 3=0,995\end{array}$ \\
\hline Несфатин-1, нг/мл & $\begin{array}{c}1,0^{*} \\
(\text { ДИ } 0,1 ; 10,8)\end{array}$ & $\begin{array}{c}4,05 \\
(\text { Ди } 0,1 ; 15,0)\end{array}$ & $\begin{array}{c}11,0 \\
(\text { Ди 6,7; 21,0) }\end{array}$ & $\begin{array}{l}1: 3=0,001^{*} \\
2: 3=0,001^{*}\end{array}$ \\
\hline
\end{tabular}

Примечание. Ме - медиана; ДИ - доверительный интервал; *различия статистически значимы при сравнении исследуемых групп. 
с нормальной массой тела, особенно выраженное снижение установлено при наличии дислипидемии. Уровень несфатина-1 отрицательно коррелировал с ИМТ, содержанием жира в организме (\%ЖМ). Отмеченное повышение аппетита может быть связано как со снижением доли АКМ, так и с низким уровнем несфатина-1 в сыворотке крови у детей с ожирением.

\section{Обсуждение основного результата исследования}

Несфатин-1 относится к недавно открытым нейропептидам. Он продуцируется нейронами ядер гипоталамуса, нейроэндокринными клетками желудочно-кишечного тракта, адипоцитами и в меньшей степени - другими видами клеток. Основные свойства несфатина-1 связывают с его анорексигенным эффектом, регуляцией пищевого поведения. Установлено его выраженное воздействие на формирование массы тела, также он влияет на моторику желудочно-кишечного тракта, участвует в регуляции углеводного и энергетического обменов, репродуктивных функций $[17,18,19]$. Недостаточная выработка несфатина-1 в организме приводит к увеличению аппетита, учащению эпизодов голода, увеличению жировых отложений и массы тела, невозможности «чувствовать насыщение» $[10,19,20]$. Полученные нами данные о взаимосвязи уровня несфатина-1 с развитием ожирения, изменениями липидного обмена и увеличением жировой компоненты тела в целом соответствуют установленным ранее фактам.

Согласно данным исследований, проведенных на детской популяции, у детей с ожирением регистрировались низкие уровни несфатина-1, также отмечалась возможная важная роль в регуляции потребления пищи $[10,12,21]$ в связи с тем, что его продукция увеличивается в ответ на потребление пищи, богатой жиром. В исследовании Kim S.H. и соавт. [12] была отмечена отрицательная корреляция несфатина с хронологическим возрастом.

По данным настоящего исследования, концентрация несфатина-1 в сыворотке была статистически значимо ниже у детей с ожирением и избыточной массой тела, чем в группе с нормальной массой тела $(p<0,001)$. Установленная отрицательная взаимосвязь между уровнем несфатина-1 и ИМТ подтверждена в других исследованиях, проведенных у детей и подростков [10, 12, 21]. В нашем исследовании показано, что уровень несфатина-1 был существенно снижен у детей с дислипидемией и ожирением. Наличие отрицательной взаимосвязи между уровнем несфатина и показателями липидного обмена, долей жировой массы тела в организме указывает на важную роль этого пептида в формировании увеличенного объема жировой ткани у детей и подростков.

Роль несфатина в регуляции потребления пищи подтверждена в многочисленных исследованиях [18-24]. A. Anik и соавт. [10] не обнаружили взаимосвязи между уровнями несфатина-1 в сыворотке натощак и после приема пищи, а также предположили отсутствие кратковременного эффекта несфатина-1 в регуляции потребления пищи. Оценка взаимосвязи уровня несфатина-1 с состоянием аппетита у детей с ожирением в нашем исследовании показала наличие отрицательной корреляции между концентрацией несфатина в сыворотке крови и повышенным аппетитом (по субъективной оценке, при сборе жалоб). Вместе с тем чувство голода и увеличе- ние аппетита может быть обусловлено не только низким уровнем несфатина, но и недостаточным уровнем активной клеточной массы (\%АКМ) у детей с ожирением [25]. Полученные результаты могут указывать не только на влияние несфатина-1 на антропометрические показатели и компонентный состав тела, но и на его роль в регуляции пищевого поведения и аппетита. Необходимы дополнительные исследования, позволяющие установить роль несфатина-1 в регуляции аппетита в детской популяции.

Разумеется, роль несфатина в развитии ожирения реализуется не только через воздействие на липидный обмен, но и на углеводный $[10,12,19,21,26]$. В ранее проведенных исследованиях оценивались взаимосвязи несфатина-1 с уровнем глюкозы, инсулина, индексом инсулинорезистентности у детей. Статистически значимой разницы при сравнении уровней несфатина-1 среди пациентов с ожирением в отношении наличия резистентности к инсулину обнаружено не было $[12,21]$. В нашем исследовании проводилось определение только уровня глюкозы. Анализ зависимости содержания несфатина в сыворотке от уровня глюкозы у детей с ожирением показал наличие средней силы прямой корреляционной связи. Однако полученные нами данные неоднозначны и требуют уточнения при проведении дальнейших расширенных исследований для установления роли несфатина-1 в метаболизме глюкозы у детей с ожирением.

В нескольких работах $[23,27,28]$ показано значение несфатина в патогенезе нарушений функций сердечно-сосудистой системы, устойчивости к стрессу, развитии депрессии во взрослой популяции. О.Н. Ковалева и соавт. [26] обнаружили, что уровень несфатина-1 в сыворотке здоровых взрослых был значимо ниже, чем у пациентов с гипертонической болезнью. При анализе уровней несфатина-1 у пациентов с избыточной массой и ожирением нами было выявлено значительное повышение концентрации несфатина (до 25,1 нг/мл) в группе детей с жалобами на периодическое повышение АД. На момент проведения исследования ни один из этих пациентов не имел установленного диагноза артериальной гипертензии. Ввиду незначительного числа таких детей мы не можем сделать вывод о взаимосвязи повышения АД с уровнем несфатина-1 в сыворотке крови. Также обращает внимание, что не у всех школьников, отметивших периодические подъемы АД, были зарегистрированы аномальные уровни несфатина-1. Установленные на взрослой популяции взаимосвязи уровня несфатина-1, ожирения и повышения артериального давления в педиатрической практике изучены недостаточно [21].

При наличии плейотропных эффектов авторы считают клинически наиболее значимым участие несфатина-1 в развитии метаболического синдрома, включающего в себя прежде всего ожирение, нарушения липидного обмена и артериальную гипертензию [17, 26, 29].

Также часть исследователей рассматривают несфатин-1 как потенциальный препарат в фармакотерапии ожирения [19, 22].

Резюме дополнительного результата исследования

Анализ результатов биоимпедансометрии у школьников показал, что у детей с избыточной массой тела 
и ожирением компонентный состав тела характеризуется увеличением доли жировой массы тела на фоне снижения активной клеточной массы. Установлено наличие прямо пропорциональной зависимости между ИМТ и \%ЖМ. Показатели липидного обмена у детей с ожирением существенно не отличались от нормальных значений, однако в данной группе пациентов выявлены признаки дислипидемии. Концентрация переносчиков ХС-лПВП - апоА-1 снижалась, а содержание переносчика ХС-лПНП - апоВ увеличивалась.

\section{Обсуждение дополнительного результата}

исследования

Проведение биоимпедансного анализа тканевых компонентов по их процентному содержанию в организме позволило исключить влияние существенной разницы в массе тела в возрастных группах. Установленная взаимосвязь между значениями ИМТ и \%ЖМ подтверждает информативность определения процентного содержания жира в качестве дополнительного критерия диагностики ожирения у детей и подростков.

В детском возрасте ожирение в основном обусловлено избыточным уровнем поступления калорий в сочетании с низким уровнем физической активности [2-6, 30]. Перераспределение компонентного состава тела у детей и подростков с ожирением приводит к повышению процентного содержания ЖМ и снижению доли АКМ. Показатель \%АКМ дает интегральную оценку как уровня метаболической активности организма, являясь значимой характеристикой интенсивности обменных процессов, так и позволяет судить об уровне двигательной активности [31]. Использование биоимпедансометрии в качестве дополнительного метода диагностики ожирения у детей рекомендовано Федеральными клиническими рекомендациями [2] и является целесообразным для детальной оценки компонентного состава тела, степени развития мускулатуры и мониторинга показателей в динамике [3, 5].

Несмотря на относительно небольшую длительность заболевания, у четверти школьников с ожирением установлены патологические изменения липидного профиля. Появление признаков дислипидемии является основой для дальнейшего формирования осложнений и коморбидной патологии. Исследование липидного обмена должно проводиться всем детям с ожирением в процессе обследования и лечения на этапе первичного звена здравоохранения $[2,3]$. Это позволит комплексно подходить к профилактике и лечению избыточной массы тела, а также своевременно выявлять метаболические нарушения.

\section{Ограничения исследования}

Исследование имеет ряд ограничений, связанных с формированием выборки: небольшой размер выборки и возрастные ограничения. При формировании выборки в исследование не попали дети младше 9 и старше 15 лет, что не позволяет получить полноценное представление о распределении концентрации изученного полипептида и экстраполировать полученные результаты на всю популяцию детей. Проведение биоимпедансометрии в детском возрасте имеет ряд ограничений, обусловленных отсутствием нормативных показателей для детей и подростков [5, 31].

\section{ЗАКЛЮЧЕНИЕ}

Роль несфатина в регуляции аппетита, метаболизма липидов и глюкозы, а также его воздействие на формирование массы тела были неоднократно показаны в исследованиях. Немногочисленные исследования, проводимые на детской популяции, свидетельствуют о наличии ассоциаций между уровнем несфатина-1 и ИМТ, отмечалась возможная важная роль в регуляции потребления пищи и участии полипептида в регуляции углеводного обмена. Вместе с тем до настоящего времени не определены референсные интервалы несфатина у детей. Малоизучены роль несфатина в регуляции аппетита у детей, а также его взаимосвязи при ожирении и повышении артериального давления в детском возрасте.

Нами установлены уровни концентрации несфатина у детей с ожирением и нормальной массой тела. Выявленные нарушения липидного обмена коррелируют с выраженным снижением уровня несфатина-1 при ожирении в детском возрасте. В то же время у детей с избыточной массой тела показатели липидного обмена не были изменены, а содержание несфатина-1 снижено, но в меньшей степени, чем при ожирении. Получены данные об отрицательной взаимосвязи концентрации несфатина-1 в сыворотке с ИМТ, долей жировой массы и аппетитом. Отмеченное повышение аппетита может быть связано как со снижением доли АKM, так и с низким уровнем несфатина-1 в сыворотке крови у детей с ожирением. Это дает основание полагать, что наряду с известной ключевой ролью несфатина в регуляции пищевого поведения и аппетита он также влияет на антропометрические показатели у детей, прежде всего связанные с накоплением избыточной жировой массы и может рассматриваться как потенциальный маркер развития ожирения у детей. Приведены сведения об аномально высоких уровнях несфатина у детей с ожирением и жалобами на повышения АД, однако обнаруженные изменения требуют дальнейшего подтверждения с увеличением числа обследуемых. Полученные нами результаты обосновывают необходимость дальнейшего исследования с целью уточнения референсных интервалов концентрации несфатина-1 у детей, определения прогностического значения данного параметра при ожирении на выборках большего размера.

\section{ДОПОЛНИТЕЛЬНАЯ ИНФОРМАЦИЯ}

Источник финансирования. Подготовка и публикация рукописи проведены на личные средства авторского коллектива.

Конфликт интересов. Авторы декларируют отсутствие явных и потенциальных конфликтов интересов, связанных с публикацией настоящей статьи.

Участие авторов. Базарный В.В. - концепция исследования, написание текста; Ануфриева Е.В. - дизайн исследования, сбор и анализ полученных данных, написание текста; Максимова А.Ю. - обработка материала, анализ полученных данных; Полушина Л.Г. - обработка материала; Ковтун О.П. - концепция исследования, написание текста. Все авторы внесли значимый вклад в проведение исследования и подготовку статьи, прочли и одобрили финальную версию статьи перед публикацией. 


\section{СПИСОК ЛИТЕРАТУРЫ | REFERENCES}

1. NCD Risk Factor Collaboration (NCD-RisC). Worldwide trends in body-mass index, underweight, overweight, and obesity from 1975 to 2016: a pooled analysis of 2416 populationbased measurement studies in 128.9 million children adolescents, and adults. Lancet. 2017;390(10113):2627-2642. doi: https://doi.org/10.1016/S0140-6736(17)32129-3

2. Федеральные клинические рекомендаиии (протоколы) по ведению детей сэндокринными заболеваниями. / Под ред. Дедова И.И., Петерковой В.А. - М.: Практика; 2014. [Dedov II, Peterkova VA, editors. Federal'nyye klinicheskiye rekomendatsii (protokoly) povedeniy u detey sendokrinnymi zabolevaniyami. Moscow: Praktika; 2014. (In Russ.)]

3. Российская ассоциация эндокринологов, Российское общество по профилактике неинфекционных заболеваний, Ассоциация детских кардиологов России. Рекомендаиии по диагностике, лечению и профилактике ожирения у детей и подростков. М.: Практика; 2015. [Rossiyskaya assotsiatsiya endokrinologov, Rossiyskoe obshchestvo po profilaktike neinfektsionnykh zabolevaniy, Assotsiatsiya detskikh kardiologov Rossii. Rekomendatsii po diagnostike, lecheniyu i profilaktike ozhireniya u detey i podrostkov. Moscow: Praktika; 2015. (In Russ.)]

4. КарпушкинаА.В., Панкратова М.С. Стратегия профилактики ожирения среди детей школьного возраста (обзор литературы). // Проблемы эндокринологии.-2016. - Т. 62. №2. - C. 52-60. [Karpushkina AV, Pankratova MS. Strategy for obesity prevention among school-age children (literature review) Problems of endocrinology. 2016;62(2):52-60. (In Russ.)] doi: https://doi.org/10.14341/probl201662252-60

5. Алимова И.Л. Перспективы применения в педиатрической практике Федеральных клинических рекомендаций «Диагностика и лечение ожирения у детей и подростков». // Российский вестник перинатологии и педиатрии.- 2015. T. 60. - №1. - C. 66-70. [Alimova IL. Prospects for using the Federal Clinical Guidelines for the Diagnosis and Treatment of Obesity in Children and Adolescents in pediatric practice. Rossiiskii vestnik perinatologii i pediatrii. 2015:60(1):66-70. (In Russ.)]

6. Мартынова И.Н., Винярская И.В. Оптимизация лечебнопрофилактической помощи детям с ожирением в условиях детской поликлиники. // Российский педиатрический журнал. 2017. — T. 20. — №5. — C. 276-282. [Martynova IN, Vinyarskaya IV. Development and evaluation of the effectiveness of the health school for children with obesity under the conditions of the child polyclinic. Russian journal of pediatrics. 2017;20(5):276-282. (In Russ.)] doi: https://doi.org/10.18821/1560-9561-2017-20(5)-276-282

7. Нетребенко О.К., Украинцев С.Е., Мельникова И.Ю. Ожирение у детей: новые концепции и направления профилактики. Обзор литературы. // Вопросы современной педиатрии. 2017. — T. 16. — №5. — C. 399-405. [Netrebenko OK, Ukraintsev SE, Melnikova IY. Ozhireniye u detey: novyye kontseptsii i napravleniya profilaktiki. Obzor literatury. Voprosy sovremennoy pediatrii. 2017;16(5):399-405. (In Russ.)] doi: https://doi.org/10.15690/vsp.v16i5.1804

8. Логвинова О.В., Пойдашева А.Г., Бакулин И.С., и др. Современные представления о патогенезе ожирения и новых подходах к его коррекции. // Ожирение и метаболизм. - 2018. T. 15. - №2. - C. 11-16. [Logvinova OV, Poydasheva AG, Bakulin IS, et al. Modern concepts of the pathogenesis of obesity and new approaches to its correction. Obesity and metabolism 2018;15(2):11-16. (In Russ.)] doi: https://doi.org/10.14341/OMET9491

9. Howick K, Griffin BT, Cryan JF, Schellekens H. From Belly to Brain: Targeting the Ghrelin Receptor in Appetite and Food Intake Regulation. Int J Mol Sci. 2017;18(2). doi: https://doi.org/10.3390/ijms18020273

10. Anik A, Catli G, Abaci A, et al. Fasting and postprandial levels of a novel anorexigenic peptide nesfatin in childhood obesity. J PediatrEndocrino/Metab. 2014;27(7-8):623-628. doi: https://doi.org/10.1515/jpem-2013-0475

11. Ayada C, Toru Ü, Korkut Y. Nesfatin-1 and its effects on different systems. Hippokratia. 2015;19(1):4-10.

12. Kim SH, Ahn MB, Cho WK, et al. The relation of serum nesfatin-1 level with anthropometric and metabolic parameters in children and adolescents: A prospective observational study. Medicine (Baltimore). 2019;98(19):e15460. doi: https://doi.org/10.1097/MD.0000000000015460
13. Kuyumcu A, Kuyumcu MS, Ozbay MB, et al. Nesfatin-1: A novel regulatory peptide associated with acute myocardial infarction and Mediterranean diet. Peptides. 2019:114:10-16. doi: https://doi.org/10.1016/j.peptides.2019.04.003

14. Schalla MA, Stengel A. Current Understanding of the Role of Nesfatin-1. J Endocr Soc. 2018;2(10):1188-1206. doi: https://doi.org/10.1210/js.2018-00246

15. Who.int [Internet]. Growth reference 5-19 years.BMIfor age (5-19years) [cited 2019 May 15]. Available from: https://www.who.int/growthref/who2007_bmi_for_age/en//.

16. Ковтун О.П., Ануфриева Е.В., Неупокоева Л.Ю. Особенности компонентного состава тела у детей и подростков с избыточной массой и ожирением. // Уральский медицинский журнал. - 2019. - №6. - С.104-109. [Kovtun OP, Anufrieva EV, Neupokoeva LY. Body component composition features of children with overweight and obesity. Ural'skiy meditsinskiy zhurnal. 2019;(6):104-109. (In Russ.)] doi: https://doi.org/10.25694/URMJ.2019.06.36

17. Dore R, Levata L, Lehnert H, Schulz C. Nesfatin-1: functions and physiology of a novel regulatory peptide. J Endocrinol. 2017;232(1):R45-R65. doi: https://doi.org/10.1530/JOE-16-0361

18. Oh IS, Shimizu H, Satoh T, et al. Identification of nesfatin-1 as a satiety molecule in the hypothalamus. Nature. 2006;443(7112):709-712. doi: https://doi.org/10.1038/nature05162

19. Khalili S, Shekari Khaniani M, Afkhami F, Mansoori Derakhshan S NUCB2/Nesfatin-1: A Potent Meal Regulatory Hormone and its Role in Diabetes. Egyptian Journal of Medical Human Genetics. 2017;18(2):105-109. doi: https://doi.org/10.1016/j.ejmhg.2016.10.003

20. Stengel A, Taché Y. Role of Brain NUCB2/nesfatin-1 in the Regulation of Food Intake. Curr Pharm Des. 2013;19(39):6955-6959. doi: https://doi.org/10.2174/138161281939131127125735

21. Abaci A, Catli G, Anik A, et al. The relation of serum nesfatin-1 level with metabolic and clinical parameters in obese and healthy children. PediatrDiabetes. 2013;14(3):189-195. doi: https://doi.org/10.1111/pedi.12009

22. Finelli C, Rossano R, Padula MC, et al. Nesfatin Role as Possible New Anti Obesity Treatment. J Obes Weight Loss Ther. 2014;04(03). doi: https://doi.org/10.4172/2165-7904.1000228

23. Schalla MA, Unniappan S, Lambrecht NWG, et al. NUCB2/ nesfatin-1 - Inhibitory effects on food intake, body weight and metabolism. Peptides. 2020;128:170308. doi: https://doi.org/10.1016/j.peptides.2020.170308

24. Ramesh N, Gawli K, Pasupulleti VK, Unniappan S. Metabolic and Cardiovascular Actions of Nesfatin-1: Implications in Health and Disease. Curr Pharm Des. 2017;23(10):1453-1464. doi: https://doi.org/10.2174/1381612823666170130154407

25. Герасимчук О.А., Гирш Я.В. Композиционный состав тела у детей и подростков с ожирением. // Трансляционная медицина. 2019. — T. 6. — №1. — C. 51-57. [Gerasimchik OA, Girsh YaV. Compositional composition of the bode in obese children and adolescents. TranslationalMedicine. 2019;6(1):51-57. (In Russ.)] doi: https://doi.org/10.18705/2311-4495-2019-6-1-51-57

26. Ковалева О.Н., Ащеулова Т.В., Иванченко С.В., Гончарь А.В. Несфатин-1 и особенности липидного профиля у больных гипертонической болезнью, ассоциированной с ожирением и избыточной массой тела. // Научные ведомости Белгородского государственного университета. Серия: Медицина. Фармация. 2016. — №26. - C.44-47. [Kovalyova ON, Ashcheulova TV, Ivanchenko SV, Gonchar AV. Nesfatin-1 and lipid profile peculiarities in hypertensive patients with obesity and overweight. Nauchnye vedomosti Belgorodskogo gosudarstvennogo universiteta. Seriya: Meditsina. Farmatsiya. 2016;(26):44-47. (In Russ.)]

27. Weibert E, Hofmann T, Stengel A. Role of nesfatin-1 in anxiety, depression and the response to stress. Psychoneuroendocrinology. 2019;100:58-66. doi: https://doi.org/10.1016/j.psyneuen.2018.09.037

28. Imbrogno S, Angelone T, Cerra MC. Nesfatin-1 and the Cardiovascular System: Central and Pheripheral Actions and Cardioprotection. CurrDrugTargets. 2015;16(8):877-883. doi: https://doi.org/10.2174/1389450116666150408101431

29. Tekin T, Cicek B, Konyaligil N. Regulatory Peptide Nesfatin-1 and its Relationship with Metabolic Syndrome. Eurasian J Med. 2019;51 (3):280-284 doi: https://doi.org/10.5152/eurasianjmed.2019.18420 
30. Петеркова В.А., Таранушенко Т.Е., Киселева Н.Г., и др. Оценка показателей физического развития в детском возрасте. // Медицинский совет. — 2016. — №7. - С. 28-35.

[Peterkova VA, Taranushenko TE, Kiseleva NG., et al. Evaluation of child growth status. Medical Council. 2016;(7):28-35. (In Russ.)] doi: https://doi.org/10.21518/2079-701X-2016-07-28-35
31. Руднев С.Г., Соболева Н.П., Стерликов С.А., Николаев Д.В. Биоимпедансное исследование состава тела населения России. - М.: РИО ЦНИИОИЗ; 2014. [Rudnev SG, Soboleva NP, Sterlikov SA, Nikolaev DV. Bioimpedansnoye issledovaniye sostava tela naseleniya Rossii. Moscow: RIO TSNIIOIZ; 2014. (In Russ.)]

\section{ИНФОРМАЦИЯ ОБ АВТОРАХ [AUTHORS INFO]:}

*Ануфриева Елена Владимировна, к.м.н. [Elena V. Anufrieva, MD, PhD]; адрес: Россия, 620014 г. Екатеринбург, ул. Репина, д. 3 [address: 3 Repina street, 620014 Yekaterinburg, Russia]; ORCID: https://orcid.org/0000-0003-2727-2412; eLibrary SPIN: 9572-7395; e-mail: elena-@list.ru

Базарный Владимир Викторович, д.м.н., профессор [Vladimir V. Bazarnyi, MD, PhD, Professor]; ORCID: https://orcid.org/0000-0003-0966-9571; eLibrary SPIN:4813-8710; e-mail: vlad-bazarny@yandex.ru Максимова Арина Юрьевна [Arina Yu. Maksimova]; ORCID: https://orcid.org/0000-0001-8412-4315; eLibrary SPIN: 6921-2766; e-mail: oreshek92@list.ru

Полушина Лариса Георгиевна, к.M.H. [Larisa G. Polushina, MD, PhD]; ORCID: https://orcid.org/0000-0002-4921-7222; eLibrary SPIN: 4391-5873; e-mail: polushina-larisa@bk.ru

Ковтун Ольга Петровна, д.м.Н., профессор [Olga P. Kovtun, MD, PhD, Professor];

ORCID: https://orcid.org/0000-0002-5250-7351; eLibrary SPIN: 9919-9048; e-mail: usma@usma.ru

*Автор, ответственный за переписку / Corresponding author.

\section{ЦИТИРОВАТЬ:}

Базарный В.В., Ануфриева Е.В., Максимова А.Ю., Полушина Л.Г., Ковтун О.П. Сывороточный несфатин у детей с избыточной массой тела и ожирением // Ожирение и метаболизм. - 2020. - Т. 17. - №2. - С. 200-207. doi: https://doi.org/10.14341/omet12075

\section{TO CITE THIS ARTICLE:}

Bazarnyi VV, Anufrieva EV, Maksimova AY, Polushina LG, Kovtun OP. Serum nesfatin in overweight and obese children. Obesity and metabolism. 2020;17(2):200-207. doi: https://doi.org/10.14341/omet12075 